\title{
Photoregulation of Bioprotectant Content of Red Leaf Lettuce with Light-emitting Diodes
}

\author{
Gary W. Stutte ${ }^{1}$ and Sharon Edney \\ Dynamac Corporation, Space Life Sciences Laboratory, Kennedy Space \\ Center, FL 32899
}

\section{Tony Skerritt \\ Department of Applied Science, Limerick Institute of Technology, Limerick, Ireland}

Additional index words. anthocyanin, ORAC, antioxidant, Lactuca sativa

\begin{abstract}
Lactuca sativa cv. Outredgeous was grown under either fluorescent lamps or light-emitting diodes (LEDs) to test the hypothesis that antioxidant potential could be regulated by light quality. Red leaf lettuce was grown at $300 \mu \mathrm{mol} \cdot \mathrm{m}^{-2} \cdot \mathrm{s}^{-1}$ of photosynthetically active radiation, $1200 \mu \mathrm{mol} \cdot \mathrm{mol}^{-1} \mathrm{CO}_{2}, 23{ }^{\circ} \mathrm{C}$, and an $18 \mathrm{~h}$-light /6-h dark photoperiod in controlled-environment chambers. The LED treatments were selected to provide different amounts of red $(640 \mathrm{~nm})$, blue $(440 \mathrm{~nm})$, green $(530 \mathrm{~nm})$, and far-red $(730 \mathrm{~nm})$ light in the spectra. Total anthocyanin content and the oxygen radical absorbance capacity of the tissue were measured at harvest. The source of light had a dramatic effect on both plant growth and production of radioprotective compounds. LEDs resulted in $50 \%$ greater bioprotectant content per plant at the same light level over triphosphor fluorescent lamps. Blue LEDs $(440 \mathrm{~nm})$ appeared to regulate the metabolic pathways leading to increased concentration of bioprotective compounds in leaf tissue. LED lighting induced a number of effects on morphology that increased both accumulation of bioprotective compounds and total yield.
\end{abstract}

Exposure to the types of radiation encountered during space flight such as solar protons and helium ions beyond Earth's magnetosphere, galactic cosmic ray HZE particles (protons and particles of high atomic number and high energy), and high proton fluxes from solar proton events may cause a number of health-related problems such as the increased risk of cancer induction in astronauts (Kennedy and Todd, 2003; National Research Council, 1996). Recent studies have shown that flavonoid compounds found in many plant species have biological activities that may mitigate oxidative damage resulting from ionizing radiation-induced damage (Arora et al., 2005; Rabin et al., 2005). It is believed that a diet rich in bioactive phytochemicals could be an effective countermeasure to both reduce the effective dose of oxidative compounds and events and induce in situ repair of oxidative damage in tissue

Received for publication 1 Oct. 2008. Accepted for publication 4 Nov. 2008.

Support for this research was provided by a grant from the Core Technical Capability (CTC) Program at NASA's John F. Kennedy Space Center, FL.

We thank FÁS (Foras Áiseanna Saothair), Ireland's Training and Employment Authority, for their Science Challenge Internship support of Tony Skerritt. We also thank Patricia Bisbee for training to perform antioxidant analysis.

${ }^{1}$ To whom reprint requests should be addressed; e-mail gary.w.stutte@nasa.gov. effect of, and enhance healing from, oxidative damage (Bhatia and Jain, 2004; Rabin et al., 2005). High antioxidant capacity has been attributed to members of the flavonoid family, particularly anthocyanins. Purified anthocyanins have been found to rank highly among other phenolic antioxidants, and their capacities to absorb oxygen radicals is up to four times greater than those of ascorbic acid and vitamin E (Gould, 2004).

In addition to their health benefits, anthocyanins are a key indicator of commercial quality for many fruits, vegetables, and ornamentals. As such, treatments that can increase the accumulation of anthocyanins are of great interest and importance in agriculture. Treatments that increase the production of anthocyanin include a number of environmental stressors such as high irradiance, temperature extremes, ultraviolet radiation, mineral imbalances, water stress, mechanical injury, and pathogen attack (Gould, 2004).

A promising electric light source for controlled-environment plant growth is lightemitting diodes (LEDs), which are solid-state, durable, lightweight, extremely long-lived, and come in selectable narrow-waveband emissions that can be matched to the absorption spectra of plant pigments (Goins et al., 1997; Kim et al., 2005).

The objective of these experiments was to test the hypothesis that high anthocyanin production and antioxidant potential could be obtained when growing red leaf lettuce under LEDs.

\section{Materials and Methods} padhyay, 2005; Wheeler et al., 2002).

There is significant literature that the use of naturally occurring antioxidants can mitigate the effect of radiation damage and be an effective countermeasure to mitigate the cv. Outredgeous (Johnny's Selected Seed, Winslow, ME), were planted in $14 \times 17 \times 9$-cm

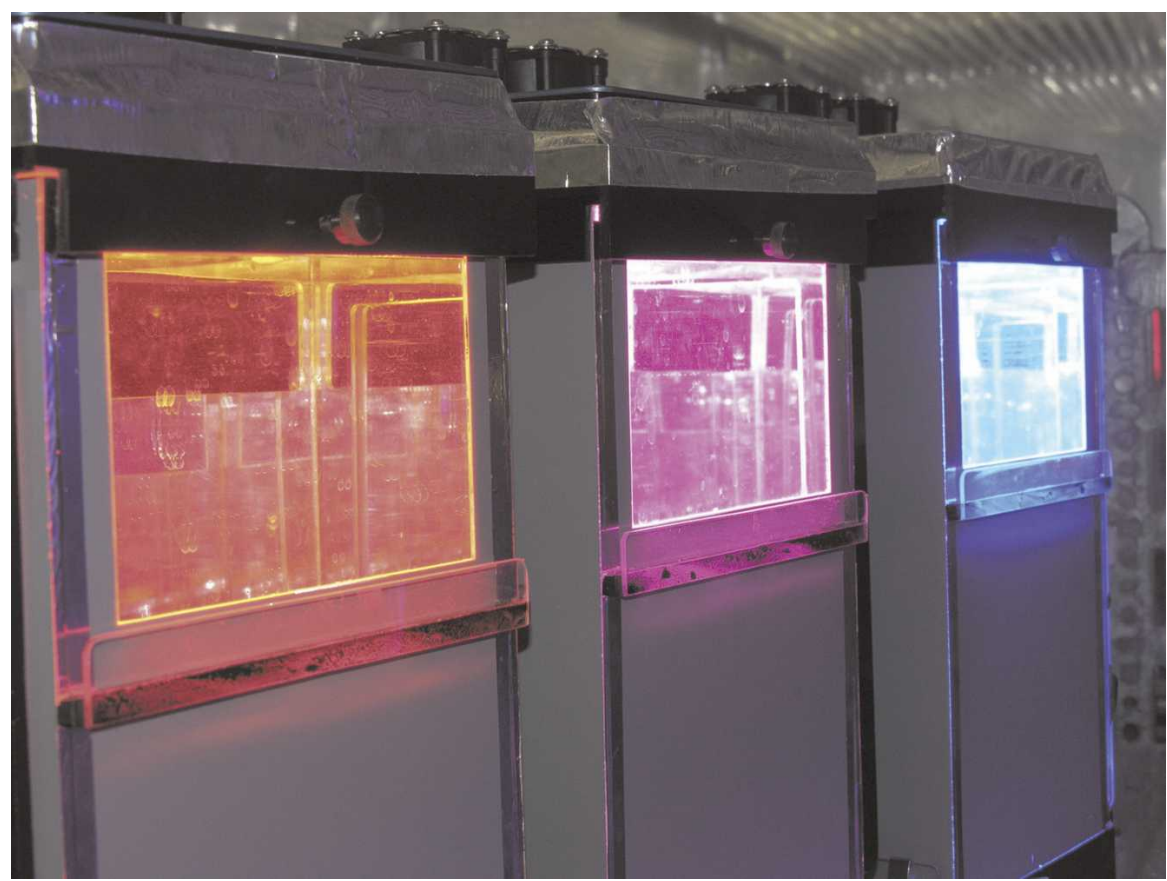

Fig. 1. Plant growth chambers with light-emitting diode (LED) arrays that allow the lighting spectra to be defined. 
Rockwool blocks (Grodan, Inc., Coppell, TX) at a density of 12 seeds per block (504 seeds $/ \mathrm{m}^{-2}$ ). Plants were grown in a walk-in growth chamber (Model M-48; EGC, Chagrin Falls, $\mathrm{OH}$ ) into which four nutrient delivery chambers were placed to allow four separate light treatments per replicate (Fig. 1). A modified full-strength Hoaglands solution
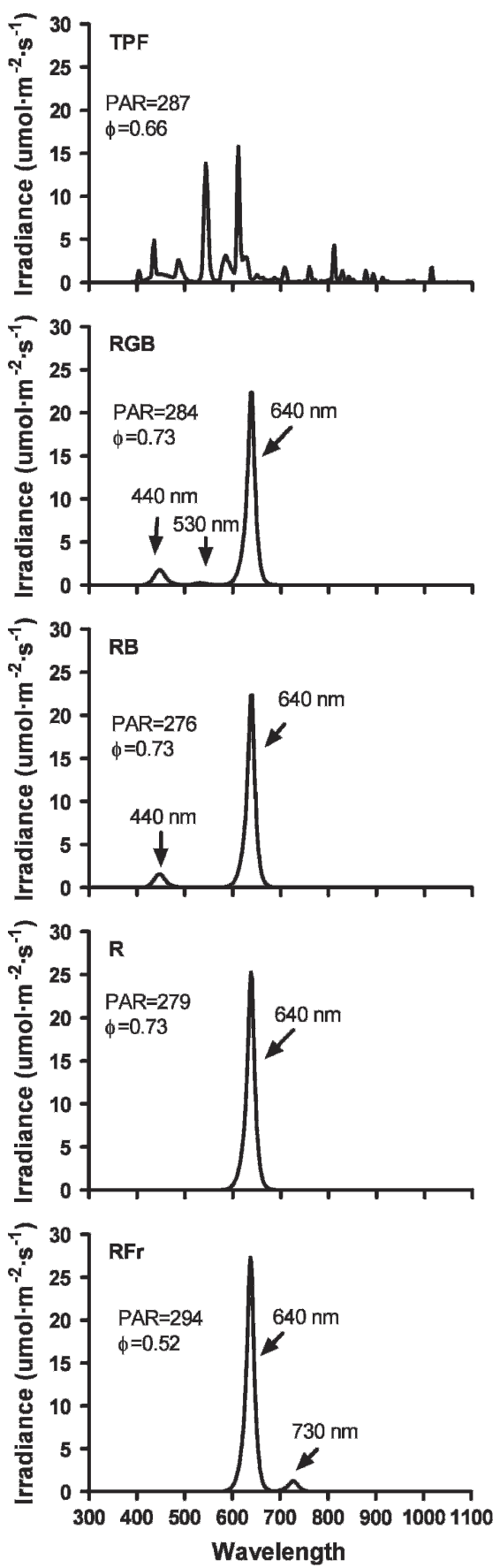

Fig. 2. Spectral distribution of irradiance from 350 to $1100 \mathrm{~nm}$ obtained at canopy level of lettuce cv. Outredgeous. Treatments included triphosphor fluorescent (TPS) lamps; red, green, and blue light-emitting diodes (LEDs; RGB); red and blue LEDs (RB); red LEDs (R); and red and far-red LEDs (RFr). The photosynthetically active radiation $(P A R)$ and the photostationary state $(\Phi)$ for each treatment are shown.
(Hoagland and Arnon, 1950) was added on a demand basis from a gravity-feed nutrientdelivery system. This allowed constant moisture content to be maintained in the root zone while meeting the nutritional demands of the plant. Water depletion from the nutrient reservoirs resulting from evapotranspiration was monitored and manually replaced in the replenishment reservoir on a daily basis. Active $\mathrm{pH}$ control was not used because the rate of replenishment of nutrient solution $(\mathrm{pH}$ $=5.8$ ) was able to maintain $\mathrm{pH}$ of solution in the media at less than 7.2. Temperature and relative humidity were maintained at $23{ }^{\circ} \mathrm{C}$ and $65 \%$, respectively, for the duration of each experiment. $\mathrm{CO}_{2}$ levels in the chamber were maintained at $1200 \mu \mathrm{mol} \cdot \mathrm{mol}^{-1}$. Plants were allowed to germinate for $5 \mathrm{~d}$ before covers were removed. Thinning of plants took place at 7 and $14 \mathrm{~d}$ to allow a final quantity of four plants per block $\left(168 / \mathrm{m}^{-2}\right)$ at harvest. Plants were grown for a total of 21 $\mathrm{d}$ to allow pigment development in the leaves to occur.

Light quality. Light quality was established using $17 \times 20$-cm high-output LED arrays with 440-, 530-, 640-, and 730-nm wavelengths programmed to provide varying quantities of each wavelength depending on the experiment (Orbitec, Madison, WI). The arrays were programmed to provide an 18 - $\mathrm{h}$ light/6-h dark photoperiod at $300 \mu \mathrm{mol} \cdot \mathrm{m}^{-2} \cdot \mathrm{s}^{-1}$ photosynthetically active radiation (PAR; $284 \pm 13 \mathrm{SD})$. This is equivalent to 19.44 $\mathrm{mol} \cdot \mathrm{m}^{-2} \cdot \mathrm{d}^{-1}$ PAR (Fig. 2). Plants grown under identical environmental conditions under triphosphor fluorescent T-8 lamps (Sylvania FP541/841/HO, Danvers, MA) at 300 $\mu \mathrm{mol} \cdot \mathrm{m}^{-2} \cdot \mathrm{s}^{-1}$ PAR $(287 \pm 14 \mathrm{sD})$ were used as control treatments. Light quality and quantity were measured using a LI-COR 1800 spectroradiometer with a cosine-corrected head (LI-COR BioSciences, Lincoln, $\mathrm{NE}$ ).

The LED treatment matrices used to determine the effect of the addition of blue and far-red light on bioprotectant production and plant morphology were: 1) RGB: 270

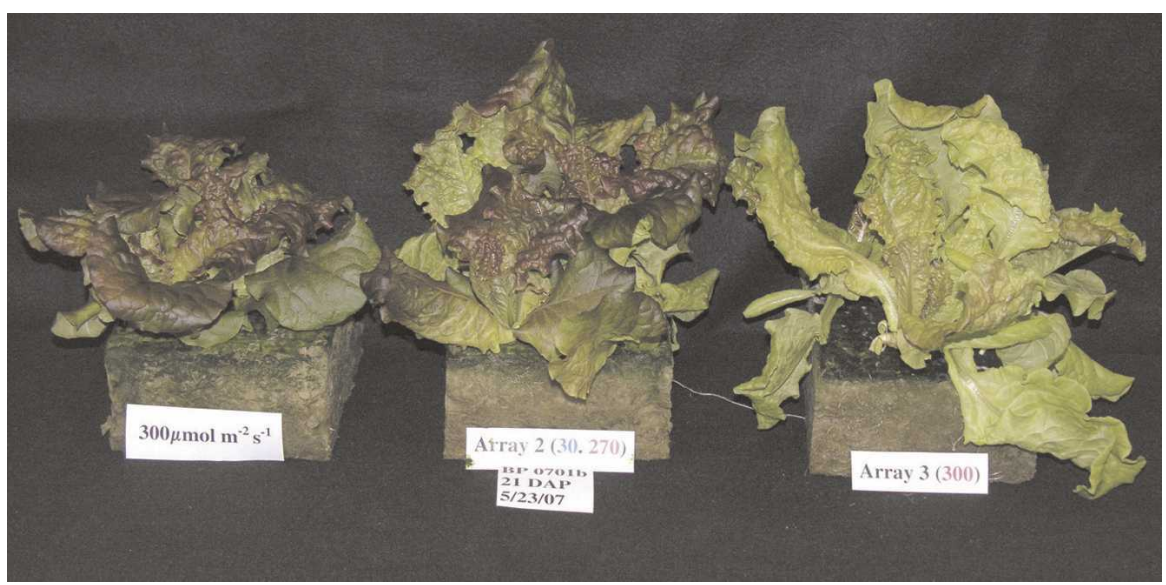

Fig. 3. Lettuce cv. Outredgeous ( $21 \mathrm{~d}$ after planting) grown under $300 \mu \mathrm{mol} \cdot \mathrm{m}^{-2} \cdot \mathrm{s}^{-1}$ photosynthetically active radiation of triphosphor fluorescent lamps (left), red and blue light-emitting diodes (LEDs; center, Array 2), and red LEDs (right, Array 3). $\mu \mathrm{mol} \cdot \mathrm{m}^{-2} \cdot \mathrm{s}^{-1} 640 \mathrm{~nm}, 5 \mu \mathrm{mol} \cdot \mathrm{m}^{-2} \cdot \mathrm{s}^{-1} 530 \mathrm{~nm}$, and $25 \mu \mathrm{mol} \cdot \mathrm{m}^{-2} \cdot \mathrm{s}^{-1} 440 \mathrm{~nm}$; 2) R: 300 $\left.\mu \mathrm{mol} \cdot \mathrm{m}^{-2} \cdot \mathrm{s}^{-1} 640 \mathrm{~nm} ; 3\right) \mathrm{BR}: 30 \mu \mathrm{mol} \cdot \mathrm{m}^{-2} \cdot \mathrm{s}^{-1}$ 440, $270 \mu \mathrm{mol} \cdot \mathrm{m}^{-2} \cdot \mathrm{s}^{-1} 640 \mathrm{~nm}$; and 4) RFr: $300 \mu \mathrm{mol} \cdot \mathrm{m}^{-2} \cdot \mathrm{s}^{-1} 640 \mathrm{~nm}, 20 \mu \mathrm{mol} \cdot \mathrm{m}^{-2} \cdot \mathrm{s}^{-1}$ $730 \mathrm{~nm}$ (Fig. 2). The experiments were repeated three times.

Plant growth measurements. Each week, canopy photomorphogenic measurements (i.e., plant height, canopy fresh weight, leaf area) were taken manually. Time-course photomorphogenic measurements were performed at 7, 14, and $21 \mathrm{~d}$ after planting. On all harvested plants, fresh weight was determined for top material only because the roots could not be quantitatively separated from the Rockwool. Plant tissues were oven-dried at $70{ }^{\circ} \mathrm{C}$ in a forced-air oven for 72 to $96 \mathrm{~h}$ before determining dry weight.

Tissue extraction. Fresh leaf lettuce (whole plant) was flash-frozen in $\mathrm{LN}_{2}$, blended in a stainless steel blender until pulverized, then ground into a fine powder using a mortar and pestle. Ground tissue was extracted in acidified methanol $(50 \% \mathrm{v} / \mathrm{v})$, centrifuged, filtered, and stored at $-80{ }^{\circ} \mathrm{C}$ until analyzed.

Oxygen radical absorbance capacity analysis. Plant extracts were analyzed for antioxidant potential using the oxygen radical absorbance capacity (ORAC) assay as described by Ou et al. (2001) using a Tecan GENios Pro plate reader (Tecan, Salzburg, Austria) equipped with a dual injection port solvent addition system. The area under the fluorescence decay curve was compared against a standard curve prepared by analyzing increasing concentrations of Trolox (6hydroxy-2,5,7,8-tetramethyl-chroman-2-carboxylic acid), a water-soluble vitamin $\mathrm{E}$ analog. ORAC antioxidant values are recorded as $\mu \mathrm{mol}$ Trolox equivalents per amount of plant sample.

Anthocyanin analysis. Plant extracts were measured for absorbance at $530 \mathrm{~nm}$ (for anthocyanin content) and $650 \mathrm{~nm}$ (for chlorophyll content) using a Beckman DU530 ultraviolet/ Vis Spectrophotometer (Beckman Coulter, Inc., Fullerton, CA). Because chlorophyll 
contributes to the absorbance of the sample at $530 \mathrm{~nm}$, a correction coefficient was used in the anthocyanin calculation as described by Mancinelli et al. (1975). Plant sample absorbances were compared against a standard curve prepared from kuromanin chloride in extraction solvent.

Statistical analysis. Data were analyzed using analysis of variance and mean separation between light treatments using Tukey's test at $P \leq 0.05$ with GraphPad Prism statistical software (GraphPad Software, San Diego, CA).

\section{Results and Discussion}

Lettuce plants grown at $19.4 \mathrm{~mol} \cdot \mathrm{m}^{-2} \cdot \mathrm{d}^{-1}$ $P A R$ under LED lights were $\approx 30 \%$ larger in total biomass then plants grown at the same light intensity under fluorescent lighting. (Fig. 3) This difference can be explained by higher photosynthetic efficiency of the light spectrum from the LED arrays than the TPS lamps. The TPS lamps had $21 \%$ of the photosynthetic photon flux in the blue region (400 to $500 \mathrm{~nm}$ ), $42 \%$ in the green (500 to 600 $\mathrm{nm})$, and $37 \%$ in the red (600 to $700 \mathrm{~nm})$, whereas the LED arrays had $95 \%$ to $100 \%$ in the red $(640 \mathrm{~nm})$ or blue $(440 \mathrm{~nm})$ wavelengths at, or near, chlorophyll absorption maxima (Fig. 2).

Anthocyanin was observed in the emerging leaves of all treatments (Figs. 3 and 4), but the pigmentation did not persist to harvest unless there was blue light in the spectra. The addition of blue light allowed full development of anthocyanin to occur (Fig. 3). The development of anthocyanin was independent of the photostationary state $(\Phi)$ of phytochrome (Fig. 4). This suggests that the effect is either a cryptochrome response or else another photoregulatory pathway is involved.

Total dry weight of plants grown under red LEDs alone was $\approx 20 \%$ lower than plants with blue or far red added (Fig. 5), although this was not statistically significant at $P \leq$ 0.05 . The addition of far red to the spectra increased total biomass over the red and blue treatments. These differences in dry weight are likely associated with photomorphogenic control of development. Emerging leaves of lettuce under red only were elongated and epinastic, limiting the total leaf area available for light reception. In contrast, the addition of blue light resulted in leaf expansion and unrolling that allowed earlier light interception. The addition of far red resulted in greater leaf elongation than red alone, but the epinastic response was less. This net effect was to increase the available leaf area for light interception over the other treatments. This indicates that the differentiation of light responses is a function of plant morphology as well as physiology.

The total amount of anthocyanin produced in the plant was significantly higher with the presence of blue light (Figs. 3, 4, and 6 ). The total content of anthocyanin in the plant is over twice as high in the presence of blue light than red alone (Fig. 7). The

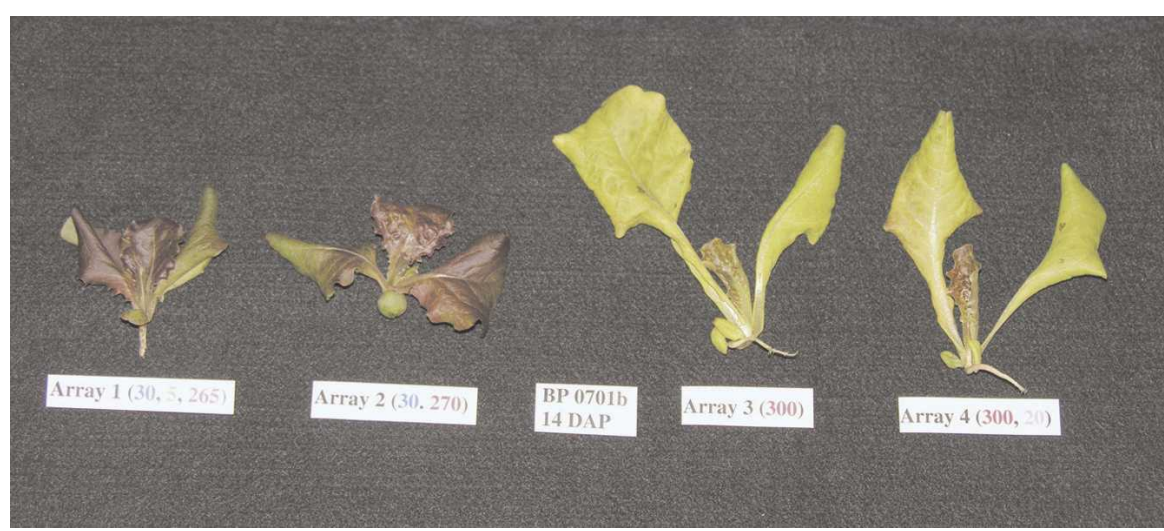

Fig. 4. Lettuce cv. Outredgeous (14 d after planting) grown under (left to right) red, green, blue (Array 1); red/blue (Array 2); red (Array 3), or red/far-red (Array 4) light-emitting diodes.

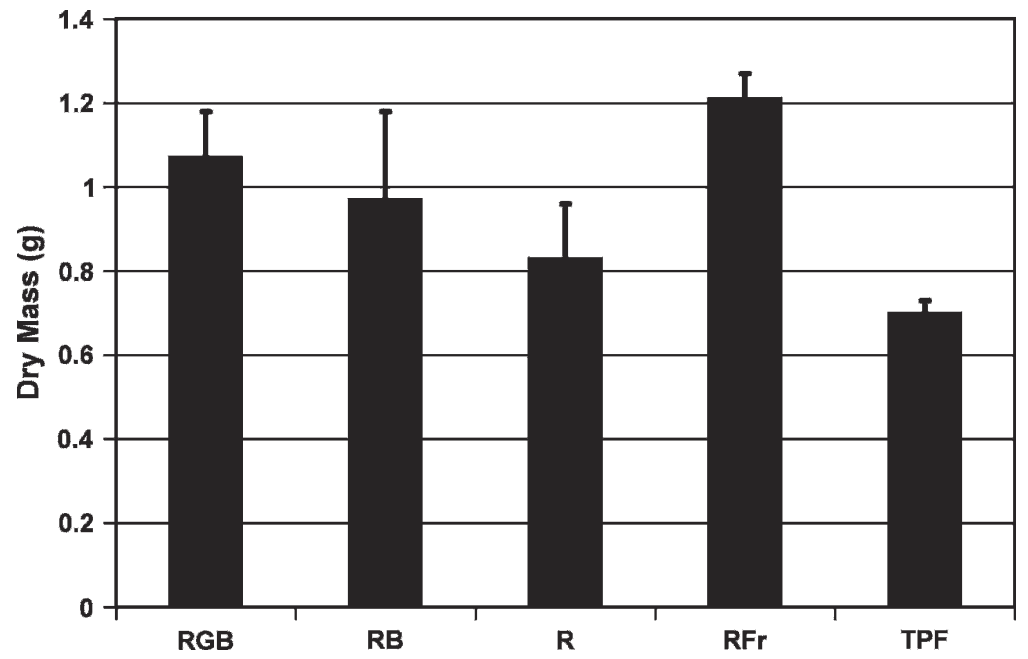

Fig. 5. Light quality affects dry weight accumulation in 21-d-old lettuce cv. Outredgeous. Treatments are: $\mathrm{RGB}=$ red $(640 \mathrm{~nm})$, green $(530 \mathrm{~nm})$, blue $(440 \mathrm{~nm}) ; \mathrm{RB}=\operatorname{red}(640 \mathrm{~nm})$, blue $(440 \mathrm{~nm}) ; \mathrm{R}=$ red $(640$ $\mathrm{nm}) ; \mathrm{RFr}=$ red $(640 \mathrm{~nm})$, far red $(730 \mathrm{~nm}) ; \mathrm{TPF}=$ triphosphor fluorescence. Error bars are sD of mean of three replicates.

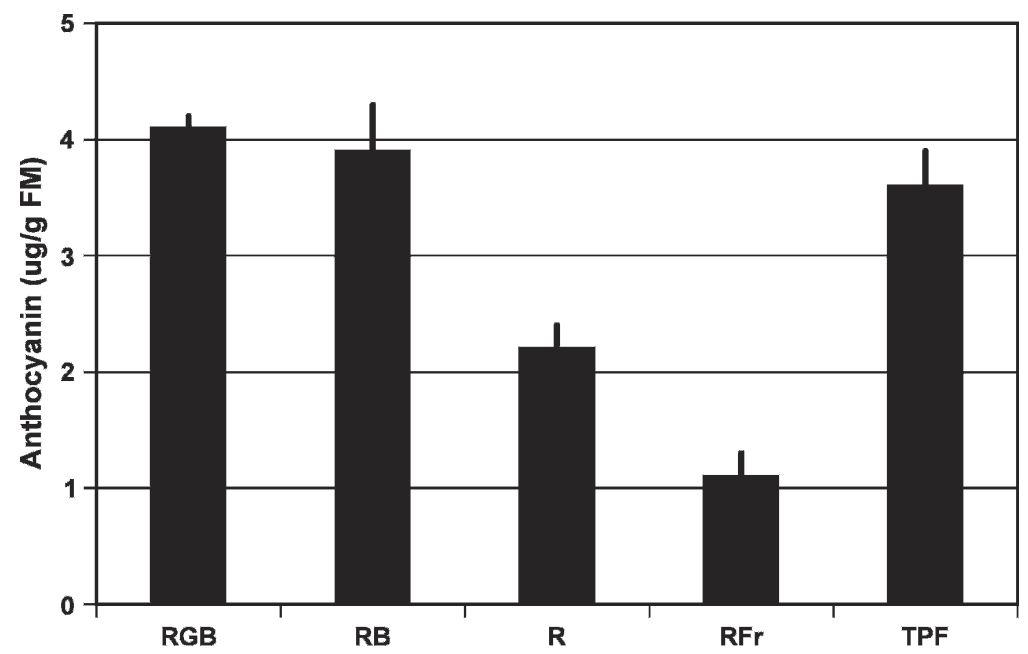

Fig. 6. Light quality affects anthocyanin concentration of 21-d-old lettuce cv. Outredgeous. Treatments are: $R G B=\operatorname{red}(640 \mathrm{~nm})$, green $(530 \mathrm{~nm})$, blue $(440 \mathrm{~nm}) ; \mathrm{RB}=\operatorname{red}(640 \mathrm{~nm})$, blue $(440 \mathrm{~nm}) ; \mathrm{R}=$ red $(640 \mathrm{~nm}) ; \mathrm{RFr}=$ red $(640 \mathrm{~nm})$, far red $(730 \mathrm{~nm}) ; \mathrm{TPF}=$ triphosphor fluorescence. Error bars are sD of mean of three replicates. 


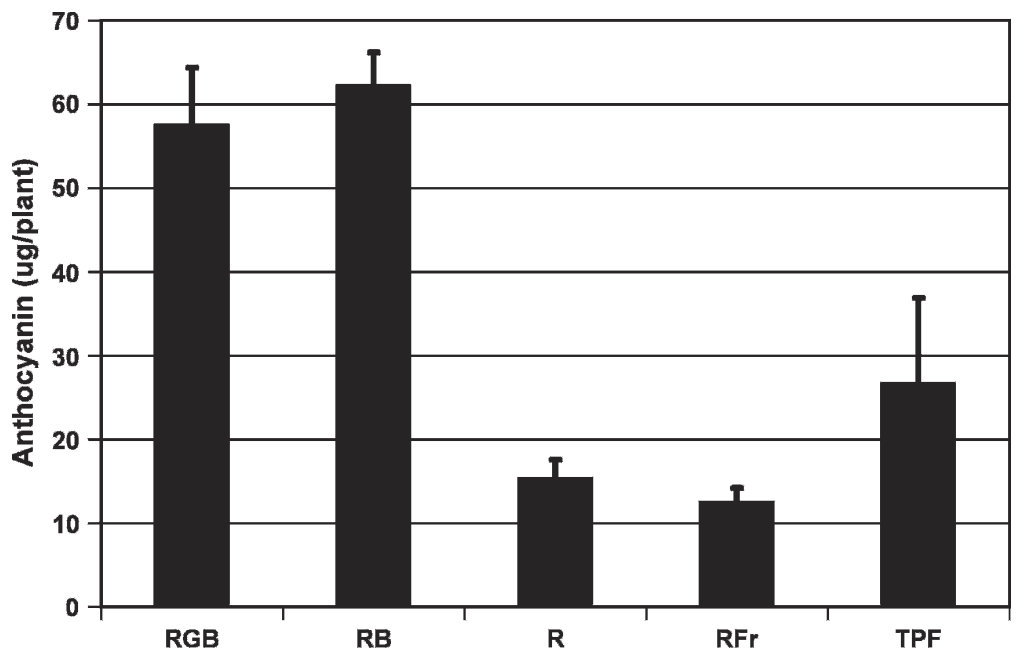

Fig. 7. Light quality affects anthocyanin content of 21-d-old lettuce cv. Outredgeous. Treatments are: $R G B=\operatorname{red}(640 \mathrm{~nm})$, green $(530 \mathrm{~nm})$, blue $(440 \mathrm{~nm}) ; \mathrm{RB}=$ red $(640 \mathrm{~nm})$, blue $(440 \mathrm{~nm}) ; \mathrm{R}=$ red $(640 \mathrm{~nm}) ; \mathrm{RFr}=$ red $(640 \mathrm{~nm})$, far red $(730 \mathrm{~nm}) ; \mathrm{TPF}=$ triphosphor fluorescence. Error bars are sD of mean of three replicates.

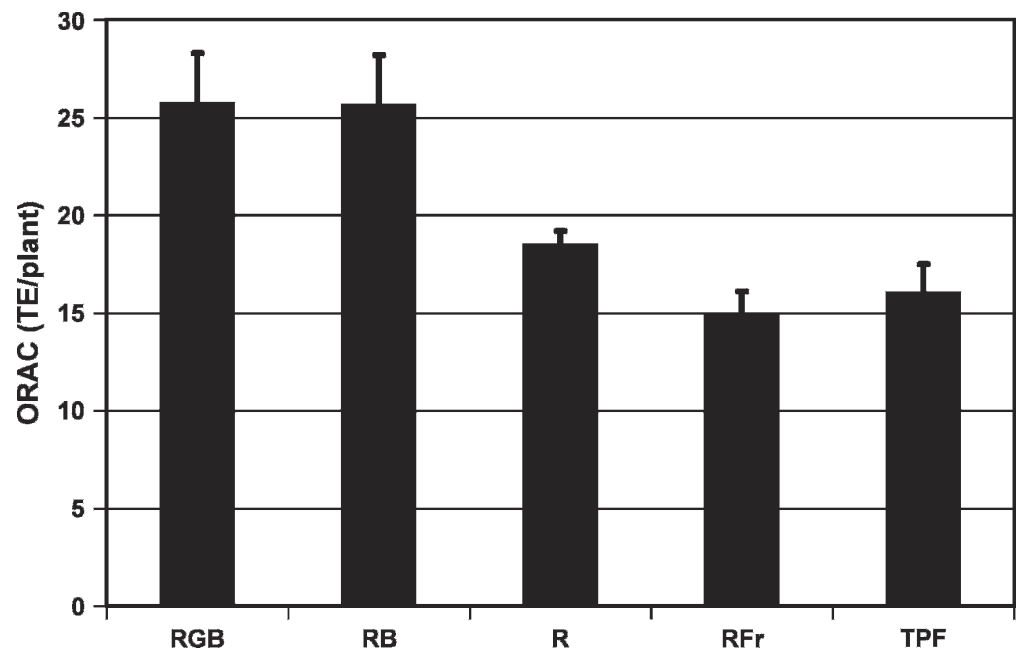

Fig. 8. Light quality affects antioxidant potential value of 21-d-old lettuce cv. Outredgeous. Treatments are: $\mathrm{RGB}=\operatorname{red}(640 \mathrm{~nm})$, green $(530 \mathrm{~nm})$, blue $(440 \mathrm{~nm}) ; \mathrm{RB}=$ red $(640 \mathrm{~nm})$, blue $(440 \mathrm{~nm}) ; \mathrm{R}=$ red $(640 \mathrm{~nm}) ; \mathrm{RFr}=$ red $(640 \mathrm{~nm})$, far red $(730 \mathrm{~nm}) \mathrm{TPF}=$ triphosphor fluorescence. Error bars are SD of mean of three replicates. The oxidative potential is based on the oxygen radical absorbance capacity (ORAC) assay and is expressed as $\mu \mathrm{mol}$ Trolox equivalents (TEs) per plant.

addition of green wavelengths to the spectra had no additional effect on anthocyanin concentration or content in the leaf. The addition of far red resulted in a slight, but not statistically significant, reduction in the anthocyanin content in the leaf.

The effects of light quality on the induction and maintenance of anthocyanin concentration are reflected in the total antioxidant potential in the leaf (Fig. 8). The addition of blue light increased the total ORAC value by $\approx 20 \%$. The addition of far red reduces the total ORAC by a comparable amount. This difference in total antioxidant potential is less than that shown for anthocyanin alone. This is consistent with other studies showing that many compounds other than anthocyanin such as isoflavonoids, carotenoids, and polyphenols also have antioxygen capabilities (Caldwell, 2003).

These data indicate that the bioprotectant properties of red leaf lettuce can be increased by altering the spectral quality of light. The use of LEDs as the light source resulted in a $30 \%$ increase in total dry weight over broadspectrum fluorescent lamps without any increase in power requirements. This suggests LED lighting to increase bioprotectant content of salad crops is a potential radiation countermeasure for long-duration missions such as transit to Mars and/or a surface habitat on the lunar or Mars surface.
Additional work is required to identify the complex mixture of flavonoids that have bioprotective properties and elucidate the photoregulatory control of their synthesis and degradation.

\section{Literature Cited}

Arora, R., D. Gupta, R. Chawla, R. Sagar, A. Sharma, R. Kumar, J. Prasad, S. Singh, N. Samanta, and R. Sharma. 2005. Radioprotection by plant products: Present status and future prospects. Phytother. Res. 19:1-22.

Bhatia, A. and M. Jain. 2004. Spinacia oleracea L. protects against gamma radiations: A study on glutathione and lipid peroxidation in mouse liver. Phytomedicine 11:607-615.

Caldwell, C.R. 2003. Alkylperoxyl radical scavenging activity of red leaf lettuce (Lactuca sativa L.) phenolics. J. Agr. Food Chem. 51: 4589-4595.

Goins, G.D., N.C. Yorio, M.M. Sanwo, and C.S. Brown. 1997. Photomorphogenesis, photosynthesis, and seed yield of wheat plants grown under red light-emitting diodes (LEDs) with and without supplemental blue lighting. J. Expt. Bot. 48:1407-1413.

Gould, K.S. 2004. Nature's Swiss Army knife: The diverse protective roles of anthocyanins in leaves. J. Biomed. Biotechnol. 5:314-320.

Hoagland, D.R. and D.I. Arnon. 1950. The water culture method for growing plants without soil. Calif. Agr. Expt. Stat. Circ. 347. Univ. of California, Berkley, CA.

Kennedy, A.R. and P. Todd. 2003. Biological countermeasures in space radiation health. Gravit. Space Biol. Bull. 16:37-44.

Kim, H.H., R.M. Wheeler, J.C. Sager, N.C. Yorio, and G.D. Goins. 2005. Light-emitting diodes as an illumination source for plants: A review of research at Kennedy Space Center. Habitation (Elmsford) 10:71-78.

Mancinelli, A.L., C.-P.H. Yang, P. Lindquist, O.R Anderson, and I. Rabino. 1975. Photocontrol of anthocyanin synthesis. Plant Physiol. 55:251-257.

National Research Council. 1996. Task group on the biological effects of space radiation, Space Studies Board. Radiation hazards to crews of interplanetary missions-Biological issues and research strategies. National Academy Science, Washington, DC.

Ou, B., M. Hampsch-Woodill, and R. Prior. 2001. Development and validation of an improved oxygen radical absorbance capacity assay using fluorescein as the fluorescent probe. J. Agr. Food Chem. 49:4619-4626.

Rabin, B.M., B. Shukitt-Hale, J. Joseph, and P. Todd. 2005. Diet as a factor in behavioral radiation protection following exposure to heavy particles. Grav. Space Biol. 18:71-77.

Stutte, G.W. 1999. Phytochemicals: Implications for long duration space missions. p. 275-286. In: Cutler, S.J. and H.C. Cutler (eds.). Biologically active natural products and agrochemicals. CRC Press, Boca Raton, FL.

Venkatachalam, S.R. and S. Chattopadhyay. 2005. Natural radioprotective agents: An overview. Curr. Org. Chem. 9:389-404.

Wheeler, R.M., G.W. Stutte, G.V. Subbarao, and N.C. Yorio. 2002. Plant growth and human life support for space travel, p. 925-941. In: Pessarakli, M. (ed.). Handbook of plant and crop physiology. 2nd Ed. Marcel Dekker, New York, NY. 